School support: Unmasking the mediating role of teachers, peers, and school administrators support towards the promotion of student engagement

$\mathrm{Hu}$, Yueh-Luen

Department of Education, National ChengChi University, Taiwan (joyhu@nccu.edu.tw)

Ching, Gregory S. $\varangle$

Graduate Institute of Educational Leadership and Development, Fu Jen Catholic University, Taiwan (gregory_ching@yahoo.com; 094478@mail.fiu.edu.tw)

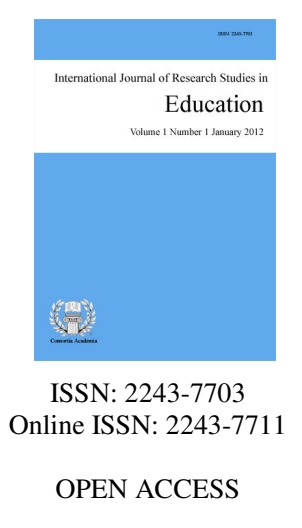

\title{
Abstract
}

The relationship of quality education and student engagement has long been in discussion. Researches have proven the persistent effects of student engagement in higher education participation and completion rate. In Taiwan, the research within the concept of student engagement is also important. Previous research using the Taiwan Survey of Student Engagement (TSSE) on students of Chinese academies called Shuyuan have proven the mediating effects of student-faculty interaction between the student engagement factors and students' educational outcome gains. With the concept of support deemed as also a key factor in student-faculty interaction, the current study focuses on proving this hypothesis. Participants of the study are 2,451 undergraduate students enrolled in four residential colleges in Taiwan. Students are from the National Tsing Hua University, Tung Hai University, National Chung Cheng University, and National ChengChi University are surveyed. Structural equation modelling was used to compute for the mediational effects. Results show that teachers, peers, and administrators supports are all crucial in mediating the effects of student engagement. Although statistical analysis shows that school support only partially mediate the educational outcome gains, the current study proves that quality school interaction should not only be limited to faculty towards students. More important, quality positive interactions should be encouraged among students and school administrators.

Keywords: student engagement; mediation; student-faculty interaction; peer support; teacher support; administrators support 


\section{School support: Unmasking the mediating role of teachers, peers, and school administrators support towards the promotion of student engagement}

\section{Introduction}

For the past decade, the concept of student engagement in higher education has shed light to its persistent effects, such as the increased in college participation and completion rate (Kuh, 2009; Kuh, Cruce, Shoup, Kinzie, \& Gonyea, 2008). More recently, development of the theory has already encompassed various implications and adaptations, such as: engagement within online learning courses (Bolliger \& Halupa, 2018; Lemanski \& Van Deventer, 2019), engagement within game-based learning (Alsawaier, 2018), engagement for indigenous students (Carter, Hollinsworth, Raciti, \& Gilbey, 2018), engagement of students in university decision making (Carey, 2018), and many others. These adaptations further strengthen the importance of the concept of engagement within learning, more specifically, the role teachers played in enhancing student interactions (Y.-L. Hu, Hung, \& Ching, 2015; Määttä \& Uusiautti, 2012).

In Taiwan, the research within the concept of student engagement is also important. Hu, Ching, and Chao (2012) used the original concepts of student engagement popularized by the National Survey of Student Engagement (NSSE) in the US (Kuh, 2001, 2009) and compared the Taiwan national Freshman-Junior Student Survey. Within their study, they filtered out items with similar latent concepts of the NSSE and categorized the data into the five effective educational benchmark practices and three educational outcome gains, which formed the Taiwan version of NSSE. The Taiwan Survey of Student Engagement (TSSE) was later used on students of Chinese academies called Shuyuan or more commonly referred to as residential colleges, 724 students were surveyed with results showing that the student-faculty interaction successfully mediated the effects between the student engagement factors and students' educational outcome gains (Y.-L. Hu, Hung et al., 2015).

Student-faculty interaction have long been noted to provide support for college students' intellectual and social development (Endo \& Harpel, 1982). In other words, meaningful interactions between teachers and students promote learning and personal development (Kuh \& Hu, 2001). Interactions between faculty and students actually promotes motivation (Komarraju, Musulkin, \& Bhattacharya, 2010), while motivations do played an important role in the process of learning development (Hsieh, 2016). In essence, students are more motivated when more interaction is made, in some sense, a wider concept of student-faculty interaction should not be limited to teacher, but should include interaction and support from school administrators and classmates.

\subsection{Role of support}

Within these concepts, interactions are quite related to the support the students received when in school. Support in a wider term; social support can be defined as the exchange of resources between two individuals, which is intended to enhance the well-being of the recipient (Shumaker \& Brownell, 1984). Besides being able to provide a sense of coping and relieves stress within new situations (Pearson, 1986), social support if done appropriately its effect is said to be able to persists (Sarason, Sarason, Shearin, \& Pierce, 1987). Quite similar with the effects of student engagement, wherein its effects are also expected to persists (Kuh et al., 2008).

Social support is said to be multi-dimensional, more important, the source of support is equally important (Zimet, Dahlem, Zimet, \& Farley, 1988). In addition, the frequency of encounters or interactions also matters (Kaplan, Cassel, \& Gore, 1977). Research have shown that the support students encounters within school acts as a buffering effect and help in enhancing academic performance (Berger \& Milem, 1999; Malecki \& Demaray, 2006). This is said to be more obvious and evident when support is experience during the first-year in college (Wilcox, Winn, \& Fyvie-Gauld, 2005). With these having said, it would seem that support should be able to provide positive outcomes within a school setting; as with the theories of student engagement, wherein the 
ultimate goal is also to promote positive outcomes in schooling.

Studies have shown that there are various methods and scale to measure social support (Bruhn \& Philips, 1984; Heitzmann \& Kaplan, 1988). More specifically, a common subscale being used to measure social support are directed towards individuals wherein interactions are made, such as family, and/or friends (Dahlem, Zimet, \& Walker, 1991; Zimet et al., 1988), hence, most measures are thought to be multidimensional in nature (Zimet, Powell, Farley, Werkman, \& Berkoff, 1990). Some prefers to measure the functional components of social support, such as the depth or level (contents) of the interactions made (S. Cohen, Mermelstein, Kamarck, \& Hoberman, 1985). However, most scales would include two important components the person interacting (eg. family, friends, significant others) with and the quality of the interaction.

Within an academic context, social support can be considered as school support. School support can be said to be quite related to the overall organizational (or institutional) climate of a school (Bradshaw, Waasdorp, Debnam, \& Johnson, 2014). For instance, a school that fosters positive environment would tend to be more supportive (R. Cohen, Kincaid, \& Childs, 2007). More important, a supportive environment also promotes a sense of school membership (Goodenow, 1993), which also helps in building the students' psychological well-being (Turner, 1981). Anchoring on the precepts of measuring support, Malecki and Demary (2002) evaluate students' perceived quality of support as provided by their parents, teachers, classmates, and close friend. Some description of quality interactions with teachers are: understands me, helps me, listens to me; while description of quality interactions with classmates are: say nice things, ask me to join (Malecki \& Demary, 2002). In sum, school support can help develop attachment and bonding among peers, which ultimately leads to better engagement.

\section{Methodology}

\subsection{Theoretical framework}

The current study uses a quantitative paradigm and collects data with a survey. The survey is modeled within the construct of TSSE. Anchoring on the concepts of student engagement by Kuh (2001, 2009), the TSSE is administered to residential college students in Taiwan. Residential college in Taiwan are said to focused more on the development of students' teamwork, independent, and civic-mindedness (Y.-L. Hu, Ching, \& Hung, 2015). More important, residential colleges integrates non-academic activities bounded within a community that encourages interactions (Y.-L. Hu, Hung, Ching, \& Liao, 2013). Hence, this it is hypothesized that residential college students are more inclined towards the concepts of student engagement.

Figure 1 shows the hypothesized mediated model for the current study. Within the model, Student Engagement (SE) as latent independent variable (IV), School Support (SS) as latent mediator, and Educational Outcome Gains (EOG) as dependent variable (DV). Hypotheses of the study are as follows:

$>\quad$ Hypothesis 1: SE has significant positive effect on SS.

$>\quad$ Hypothesis 2: SS has significant positive effect on EOG.

$>\quad$ Hypothesis 3: SE has significant positive effect on EOG.

$>\quad$ Hypothesis 4: SS mediates the SE-EOG relationship. 


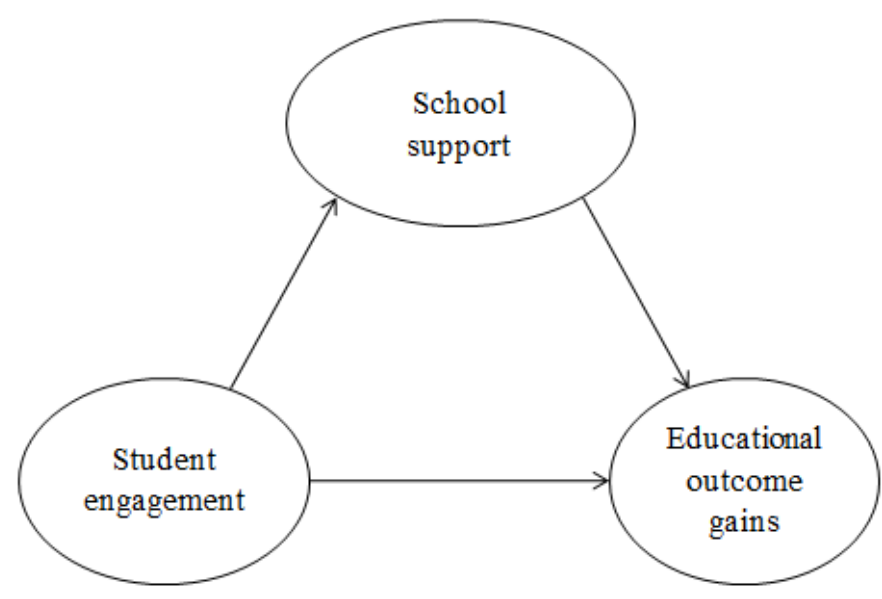

Figure 1. Hypothesized mediated model

\subsection{Participants}

This current study involved 2,451 undergraduate students enrolled in four residential colleges in Taiwan. Participants are from National Tsing Hua University with 20.8\%, Tung Hai University with $13.3 \%$, National Chung Cheng University with $10.6 \%$, and National ChengChi University with $55.3 \%$. The sample included $1,536(62.7 \%)$ women and $915(37.3 \%)$ men. Of the participants, $24.2 \%$ are freshmen, $23.1 \%$ are sophomores, $21.4 \%$ are juniors, and $31.3 \%$ are seniors university students (see Table 1 for more details).

\section{Table 1}

Background demographics of participants $(N=2,451)$

\begin{tabular}{|c|c|c|}
\hline Items & $n$ & $\%$ \\
\hline \multicolumn{3}{|l|}{ Residential colleges } \\
\hline National Tsing Hua University & 510 & 20.8 \\
\hline Tung Hai University & 326 & 13.3 \\
\hline National Chung Cheng University & 260 & 10.6 \\
\hline National ChengChi University & 1355 & 55.3 \\
\hline \multicolumn{3}{|l|}{ Gender } \\
\hline Male & 915 & 37.3 \\
\hline Female & 1536 & 62.7 \\
\hline \multicolumn{3}{|l|}{ Year level } \\
\hline Freshmen & 593 & 24.2 \\
\hline Sophomores & 566 & 23.1 \\
\hline Juniors & 525 & 21.4 \\
\hline Seniors & 767 & 31.3 \\
\hline
\end{tabular}

\subsection{Measures}

Student Engagement (SE) - SE is derived from the TSSE with special adaption for residential colleges. Four observed variables were used to measure the latent variable SE, including Active and collaborative Learning (ACL) ${ }^{1}$, Enriching Education Experiences (EEE) ${ }^{1}$, Cross-Field Learning (CFL), and Citizenship. Every observed variable used a subscale with 4-6 items; all scales uses a 7-point Likert type scale ranging from 1 to 7 , collecting the students' perceived agreement with the statement. All of the scales are reliable and valid with

\footnotetext{
${ }^{1}$ For more details regarding ACL and EEE items, please refer to "Hu, Y.-L., Ching, G. S., \& Chao, P.-C. (2012). Taiwan student engagement model: Conceptual framework and overview of psychometric properties. International Journal of Research Studies in Education, 1(1), 69-90. https://doi.org/10.5861/ijrse.2012.v1i1.19"
} 
Unmasking the role of teachers, peers, and administrators support towards the promotion of student engagement coefficient Alpha ranging from .70 .89, the explained variance ranging 51\% 71\%. CFL are items that promote multi-disciplinary learning. Not only limited to medical and engineering sciences (Gilbert, 2005; Perrenet, Bouhuijs, \& Smits, 2000), multi-disciplinary learning approaches to higher education is also applicable to the social sciences (Jacobson \& Wilensky, 2006). More important, a diverse college experience is said to be able to provide better future work skills (Engberg, 2007). Items for this variable are concentrated on the opportunity to learn and apply cross-field knowledge in the university (see Table 2 for more information). As for the variable citizenship, this is also added in reference to the core concepts of residential colleges in Taiwan (Y.-L. Hu, Ching et al., 2015; Y.-L. Hu et al., 2013). Citizenship development within higher education is always considered as an important aspect of learning (Arthur \& Bohlin, 2005; Sax, 2004). Items for this variable are more focused on the civic issues and being able to express opinions regarding topics such as fairness and social justice (see also Table 2 for more details).

Table 2

Items for Cross-Field Learning (CFL) and Citizenship

$$
\text { Cross-Field Learning (CFL) }
$$

1. Able to come across multi-disciplinary knowledge

2. Actively take courses beyond the current field of study

3. Able to integrate various different concepts learned and generate new innovative ideas

4. Be able to think and/or interpret issues from various points of view

5. Tries to integrate knowledge coming from different fields of study

\section{Citizenship}

1. Able to participate in social movements in defense of fairness and social justice

2. Take courses in civic issues and legal literacy

3. Able to participate in discussions with teachers and peers regarding democratic issues and the rule of law

4. Able to express personal opinion with regards to democratic issues and the rule of law

School Support (SS) - SS describes how students perceived the quality of interactions with their peers, teachers, and school administrators. All three of the variables used items with 7 point Likert type scale ranging from 1 to 7 denoting opposite dimensions of interactions quality. The scale is computed to be reliable and valid with a coefficient Alpha of .75, while the explained variance is computed at $67.13 \%$ (see Table 3 for more details).

Table 3

Opposite interaction ratings for school support items

\begin{tabular}{ccc}
\hline Sub-scale & \multicolumn{2}{c}{ Ratings } \\
\cline { 2 - 3 } & unfriendly & 7 \\
\hline Peers & discouraging & friendly \\
& alienated & supportive \\
& isolated & sense of belonging \\
\hline Teachers & unhelpful & accessible \\
& apathy & helpful \\
& unhelpful & empathy \\
\hline School administrators & inconsiderate & helpful \\
& rigid & thoughtful \\
& & flexible \\
\hline
\end{tabular}

Educational Outcome Gains (EOG ${ }^{2}$ ) -describes the learning outcomes within the concepts of student engagement (Kuh, 2001, 2009), which was later adapted to fit the Taiwan context (Y.-L. Hu et al., 2012). Three observed variables were used to measure the latent variable EOG, which includes: General Education Gains

\footnotetext{
${ }^{2}$ For more details regarding the EOG items, please refer to "Hu, Y.-L., Ching, G. S., \& Chao, P.-C. (2012). Taiwan student engagement model: Conceptual framework and overview of psychometric properties. International Journal of Research Studies in Education, 1(1), 69-90. https://doi.org/10.5861/ijrse.2012.v1i1.19"
} 
Hu, Y.-L., \& Ching, G. S.

(GEG), Practical Competence Gains (PCG), and Personal Social Gains (PSG). Every observed variables use a subscale with 3 to 6 items, all scales used a 7 point Likert type scale ranging from 1 to 7 . Analysis shows that the scales are reliable and valid, the coefficient Alpha ranging from .82 .90 with explained variance ranging from $52 \% \sim 73 \%$.

\subsection{Data analysis}

The entire sample of the study consists of 2,451 students coming from the four residential colleges in Taiwan. The sample were then separated into two parts by random ( $33 \%$ sample, $n=817 ; 67 \%$ sample, $n=1,634$ ). The 33\% sample was used in the measurement model for the Confirmatory Factor Analysis, CFA, while the other $67 \%$ sample was used in the structure model for the path analysis and mediation test. Descriptive statistics and correlation estimation were computed using the SPSS version 21 software program, while the composite reliability (CR) and average variance extracted (AVE) were used to prove the reliability and validity of the measurement model. Structure model was used to explain the relationship and effects among latent variables. Structure equation modeling (SEM) was estimated using the maximum-likelihood method in the AMOS version 20 software program (Arbuckle, 2011).

\section{Results and discussions}

\subsection{Preliminary analysis}

Means, standard deviations (SD), and zero-order correlations for the 10 measured variables are computed and shown in Table 4. Since, the number of items is not equal in every variable, during the analysis the mean values were deliberately used to represent the items. All of the means of the observed variables ranges from 3.67 5.02 with SD ranging from 1.07 1.45. Multivariate normality test was used to examine whether the data met the normality assumptions underlying the maximum-likelihood procedure used to test the models in the present study. The results of the multivariate normality test indicated that the data were multivariate normal, multivariate kurtosis $<24$. Therefore, maximum-likelihood method is computed to be appropriate.

\section{Table 4}

Means, standard deviations, and zero-order correlations matrix $(N=2,451)$

\begin{tabular}{llllllllllllll}
\hline & \multicolumn{1}{c}{ Item } & Mean & SD & $\mathbf{1}$ & $\mathbf{2}$ & $\mathbf{3}$ & $\mathbf{4}$ & $\mathbf{5}$ & $\mathbf{6}$ & $\mathbf{7}$ & $\mathbf{8}$ & $\mathbf{9}$ & $\mathbf{1 0}$ \\
\hline $\mathbf{1}$ & ACL & 4.69 & 1.16 & 1 & & & & & & & & \\
$\mathbf{2}$ & EEE & 4.51 & 1.07 & .65 & 1 & & & & & & & \\
$\mathbf{3}$ & CFL & 4.82 & 1.13 & .57 & .59 & 1 & & & & & & \\
$\mathbf{4}$ & Citizenship & 3.35 & 1.36 & .40 & .56 & .48 & 1 & & & & & \\
$\mathbf{5}$ & Peer support & 5.02 & 1.20 & .41 & .40 & .31 & .17 & 1 & & & & \\
$\mathbf{6}$ & Teacher support & 4.95 & 1.31 & .35 & .27 & .26 & .11 & .54 & 1 & & & \\
$\mathbf{7}$ & Administration support & 4.21 & 1.45 & .25 & .22 & .18 & .12 & .43 & .55 & 1 & & \\
$\mathbf{8}$ & GEG & 4.54 & 1.12 & .43 & .44 & .40 & .33 & .48 & .43 & .35 & 1 & \\
$\mathbf{9}$ & PCG & 4.60 & 1.16 & .40 & .34 & .34 & .17 & .44 & .34 & .24 & .76 & 1 \\
$\mathbf{1 0}$ & PSG & 4.82 & 1.14 & .45 & .45 & .42 & .28 & .52 & .47 & .40 & .86 & .71 & 1 \\
\hline
\end{tabular}

\subsection{Measurement model}

The analysis for the measurement follows the guide from Anderson and Gerbing (1988) suggested conducting a confirmatory factor analysis in order to examine whether the measurement model provides an acceptable fit to the data. Once an acceptable measurement model is developed, the structural model can be tested. Five fit indices were used to assess the goodness of fit for the models: the Goodness of Fit Index (GFI; values $>0.90$ indicate good fit), the Comparative Fit Index (CFI; values $>0.90$ indicate good fit), the Tucker-Lewis Index (TLI; values $>0.90$ indicate good fit), the Non-normed Fit Index (NFI; values $>0.90$ 
Unmasking the role of teachers, peers, and administrators support towards the promotion of student engagement indicate good fit), and the Root-Mean-Square Error of Approximation (RMSEA; values < 0.08 indicate good fit) (Byrne, 2001; L. T. Hu \& Bentler, 1999; Tucker \& Lewis, 1973).

A test of the measurement model resulted in a relatively good fit to the data $\left(\chi^{2}=115.03, d f=41, \mathrm{GFI}=.94\right.$, $\mathrm{CFI}=.96$, TLI $=.95, \mathrm{NFI}=.95$, and RMSEA $=.071)$. All of the standardized loadings of the measured variables on the latent variables were greater than .54 and are computed to be statistically significant with $p$ $<.001$ (see Table 5 for more details). CR of the latent variables were computed to be ranging from .71 .93 with the AVE ranging from .46 .77, both CR and AVE are computed to be fit to the acceptable standards (Fornell \& Larcker, 1981; Hair, Black, Babin, \& Anderson, 2010). Therefore, all of the latent variables appear to have been adequately operationalized by their respective indicators. In addition, correlations among the independent latent variables, the mediator latent variable, and dependent latent variables were all statistically significant with $p$ $<.001$ (refer to Table 6 and Table 7 for more information).

\section{Table 5}

Model fit indices

\begin{tabular}{cccc}
\hline Indices & Measurement model & Structural model & Criteria \\
\hline$n$ & 817 & 1634 & \\
$\chi^{2}$ & $251.49^{* * *}$ & $348.69^{* * *}$ & \\
$d f$ & 36 & 34 & \\
GFI & .945 & .966 & $>.90$ \\
CFI & .960 & .976 & $>.90$ \\
TLI & .939 & .961 & $>.90$ \\
NFI & .958 & .974 & $>.90$ \\
RMSEA & .078 & .070 & $<.08$ \\
\hline Note. ${ }^{* * *} p<.001$ & & &
\end{tabular}

Table 6

Factor loadings for the measurement model (33\% sample, $n=817$ )

\begin{tabular}{|c|c|c|c|c|c|}
\hline Factors and Items & Standardized Factor Loading & $S E$ & $t$ & $A V E$ & $C R$ \\
\hline Student Engagement(SE) & & & & .57 & .84 \\
\hline $\mathrm{ACL}$ & .94 & & & & \\
\hline EEE & 69 & .024 & 29.55 & & \\
\hline CFL & .82 & .030 & 36.95 & & \\
\hline Citizenship & .59 & .026 & 34.69 & & \\
\hline School Support(SS) & & & & .46 & .71 \\
\hline Peer support & .76 & & & & \\
\hline Teacher support & .70 & .037 & 24.88 & & \\
\hline Administration support & .54 & .039 & 20.87 & & \\
\hline Educational Outcome Gains (EOG) & & & & .77 & .93 \\
\hline GEG & .97 & .014 & 56.12 & & \\
\hline PCG & .78 & .009 & 119.47 & & \\
\hline PSG & .97 & .014 & 59.67 & & \\
\hline
\end{tabular}

Note. All standardized factor loading are significant with $p<.001$.

Table 7

Correlations matrix for the measurement model (33\% sample, $n=817$ )

\begin{tabular}{llll}
\hline \multicolumn{1}{c}{ Latent Variables } & 1 & 2 & 3 \\
\hline 1. Student engagement(SE) & 1 & & \\
2. School support(SS) & .52 & 1 & \\
3. Educational outcome gains (EOG) & .52 & .63 & 1 \\
\hline Note. All values of correlation are significant with $p<.001$. & & &
\end{tabular}




\subsection{Structural model for testing the mediated effects}

Within the previous sections, the analysis on the measurement model provided insights on how the data is organized and validated. The next section will test the validity of the structural models, more specifically; this section will test whether SS is able to mediate the effects of SE towards EOG. Using SE as the latent IV, SS as the latent mediator, and EOG as DV, SEM analysis showed a good fit of the model to the data $\left(\chi^{2}=178.07, d f=\right.$ $51, \mathrm{GFI}=.95, \mathrm{CFI}=.97, \mathrm{TLI}=.96, \mathrm{NFI}=.96, \mathrm{RMSEA}=.068)$. Noting that path effect is mostly referred to as the direct effect, analysis also shows that all the effect sizes of structural paths were medium and significant with $p<.001$ (see Table 8 and Figure 2 for more details).

\section{Table 8}

Bootstrap analysis of structural model (67\% sample, $n=1,634)$

\begin{tabular}{clcc}
\hline Hypothesis & \multicolumn{1}{c}{ Path } & Standardized coefficient & $95 \%$ CI \\
\hline H1 & SE $\rightarrow$ SS & $.48^{* * * *}$ & \\
H2 & SS $\rightarrow$ EOG & $.55^{* * * *}$ & \\
H3 & SE $\rightarrow$ EOG & $.21^{* * *}$ & $.227 \sim .305$ \\
H4 & SE $\rightarrow$ SS $\rightarrow$ EOG & .26 & \\
\hline Note. ${ }^{* * *} p<.001$. & & &
\end{tabular}

Within mediation testing, numerous approaches can be used to examine while considering Type I error and statistical power (MacKinnon, Lockwood, Hoffman, West, \& Sheets, 2002). To date, the most often used strategy by Baron and Kenny (1986) is proven to have the least power. Many studies using this approach have much relied on the Sobel (1982) to examine the significance of mediation effect. However, there is also evidence that the distribution of mediation effect using this method is not normal (Mackinnon \& Dwyer, 1993), and the utilization of a significance test, such as the Sobel test, which assumes a normal distribution when examining the mediation effect, is not appropriate. More recently, Shrout and Bolger (2002) suggest bootstrap method can be a better way to examine mediation. Bootstrap method acquires $95 \%$ of the confidence intervals (CI) for the indirect effect by resampling procedure. Based on central limit theorem, bootstrap method is robust even the distribution of mediation effect is not normal. Using Shrout and Bolger's suggestion, if the 95\% CI for the estimates of the indirect effects based on these 5000 indirect effect estimates does not include zero, then it can be concluded that the indirect effect is statistically significant at the .05 level. Therefore, after the structural models were examined through the AMOS software program, the bootstrap procedure was used to test whether or not the indirect effects were statistically significant.

Mediation effect is frequently referred to as indirect effect was .26. The $95 \% \mathrm{CI}$ for the estimates of the indirect effects ranging .227 .305 does not include zero; then it can be concluded that the indirect effect is statistically significant at the .05 level. For residential college students, SS plays a role as mediator between SE and EOG. Total effect is the summation of direct effect and indirect effect, the total effect was .47, the 95\% CI for total effects ranging .431 .521 does not include zero; the total effect is statistically significant at the .05 level. The results of structure model shown the theory model can explain educational outcome gains well for our sample. As above, both hypotheses are supported. In addition, according to Baron and Kenny (1986), because the direct effect is still significant, our model is considered as a partial mediation, in essence, it is noted there may be other effective mediator that can be taken into consideration in the future. 


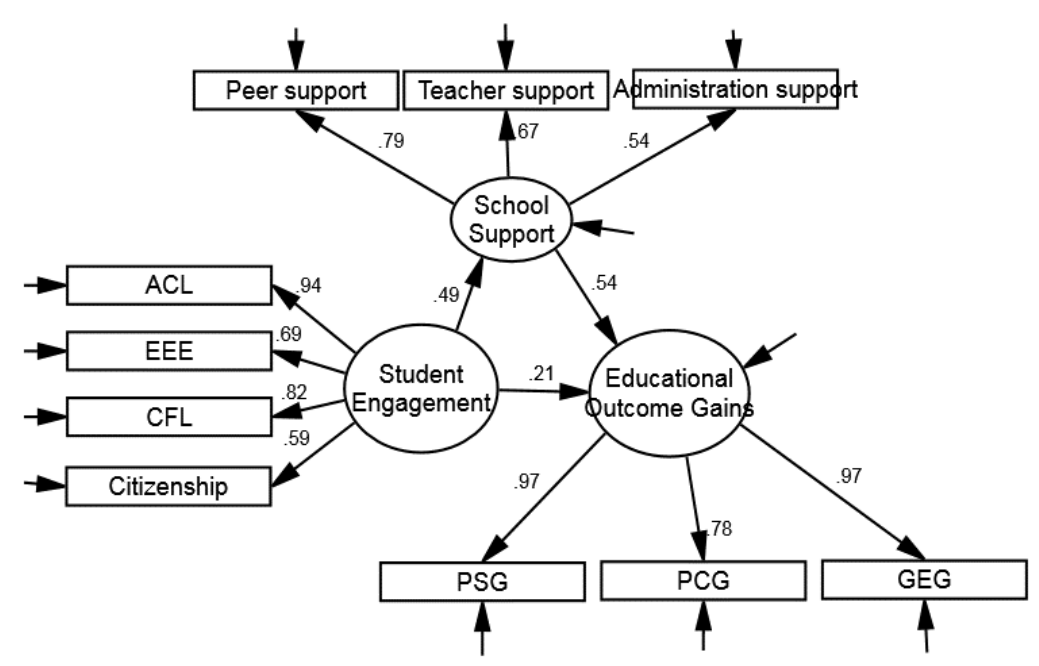

Figure 2. Full model of the study

\section{Conclusions}

Anchoring within the concept of support, which is deemed as also a key factor in student-faculty interaction, the current study focuses on understanding the relationship of school support within the interaction of student engagement and educational outcome gains. Participants of the study are 2,451 undergraduate students enrolled in four residential colleges in Taiwan. Students are from the National Tsing Hua University, Tung Hai University, National Chung Cheng University, and National ChengChi University are surveyed. Structural equation modelling was used to compute for the mediational effects. Results show that teachers, peers, and administrators supports are all crucial in mediating the effects of student engagement. Although statistical analysis shows that school support only partially mediate the educational outcome gains, the current study proves that quality school interaction should not only be limited to faculty towards students. More important, quality positive interactions should be encouraged among students and school administrators. To encourage quality interactions within schools, more specifically among the students, a healthy positive atmosphere (organizational climate) must be present. Some argues that it is not only limited to have a learning atmosphere, the school should also have a positive atmosphere. This climate should foster trust and competence. In essence, a positive organizational climate benefits the entire stakeholder within the school, hence, encourage supports.

\section{References}

Alsawaier, R. S. (2018). The effect of gamification on motivation and engagement. The International Journal of Information and Learning Technology, 35(1), 56-79. https://doi.org/10.1108/IJILT-02-2017-0009

Anderson, J. C., \& Gerbing, D. W. (1988). Structural equation modeling in practice: A review and recommended two-step approach. Psychological Bulletin, 103(3), 411-423. https://doi.org/10.1037/0033-2909.103.3.411

Arbuckle, J. L. (2011). IBM SPSS Amos 2.0 user's guide. Armonk, NY: IBM.

Arthur, J., \& Bohlin, K. E. (Eds.). (2005). Citizenship and higher education: The role of universities in communities and society. Milton Park: Routledge Falmer. https://doi.org/10.4324/9780203415931

Baron, R. M., \& Kenny, D. A. (1986). The moderator-mediator variable distinction in social psychological research: Conceptual, strategic, and statistical considerations. Journal of Personality and Social Psychology, 51(6), 1173-1182. https://doi.org/10.1037/0022-3514.51.6.1173

Berger, J. B., \& Milem, J. F. (1999). The role of student involvement and perceptions of integration in a causal model of student persistence. Research in Higher Education, 40(6), 641-664. https://doi.org/10.1023/A:1018708813711

Bolliger, D. U., \& Halupa, C. (2018). Online student perceptions of engagement, transactional distance, and outcomes. Distance Education, 39(3), 299-316. https://doi.org/10.1080/01587919.2018.1476845

Bradshaw, C. P., Waasdorp, T. E., Debnam, K. J., \& Johnson, S. L. (2014). Measuring school climate in high 
Hu, Y.-L., \& Ching, G. S.

schools: A focus on safety, engagement, and the environment. Journal of School Health, 84(9), 593-604. https://doi.org/10.1111/josh.12186

Bruhn, J. G., \& Philips, B. U. (1984). Measuring social support: A synthesis of current approaches. Journal of Behavioral Medicine, 7(2), 151-169. https://doi.org/10.1007/BF00845384

Byrne, B. M. (2001). Structural equation modeling with AMOS: Basic concepts, applications, and programming. New York, NY: Taylor and Francis Group.

Carey, P. (2018). The impact of institutional culture, policy and process on student engagement in university decision-making. Perspectives: Policy and Practice in Higher Education, 22(1), 11-18. https://doi.org/10.1080/13603108.2016.1168754

Carter, J., Hollinsworth, D., Raciti, M., \& Gilbey, K. (2018). Academic place-making: Fostering attachment, belonging and identity for Indigenous students in Australian universities. Teaching in Higher Education, 23(2), 243-260. https://doi.org/10.1080/13562517.2017.1379485

Cohen, R., Kincaid, D., \& Childs, K. E. (2007). Measuring school-wide positive behavior support implementation: Development and validation of the benchmarks of quality. Journal of Positive Behavior Interventions, 9(4), 203-213. https://doi.org/10.1177/10983007070090040301

Cohen, S., Mermelstein, R., Kamarck, T., \& Hoberman, H. M. (1985). Measuring the functional components of social support. In I. G. Sarason \& B. R. Sarason (Eds.), Social support: Theory, research and applications (Vol. 24). Dordrecht: Springer. https://doi.org/10.1007/978-94-009-5115-0_5

Dahlem, N. W., Zimet, G. D., \& Walker, R. R. (1991). The multidimensional scale of perceived social support: A confirmation study. Journal of Clinical Psychology, 47(6), 756-761. https://doi.org/10.1002/1097-4679(199111)47:6<756::AID-JCLP2270470605>3.0.CO;2-L

Endo, J. J., \& Harpel, R. L. (1982). The effect of student-faculty interaction on students' educational outcomes. Research in Higher Education, 16(2), 115-138. https://doi.org/10.1007/BF00973505

Engberg, M. E. (2007). Educating the workforce for the 21st century: A cross-disciplinary analysis of the impact of the undergraduate experience on students' development of a pluralistic orientation. Research in Higher Education, 48(3), 283-317. https://doi.org/10.1007/s11162-006-9027-2

Fornell, C., \& Larcker, D. (1981). Structural equation models with unobservable variables and measurement error. Journal of Marketing Research, 18(1), 39-50. https://doi.org/10.1177/002224378101800104

Gilbert, J. H. (2005). Interprofessional learning and higher education structural barriers. Journal of Interprofessional Care, 19(1), 87-106. https://doi.org/10.1080/13561820500067132

Goodenow, C. (1993). The psychological sense of school membership among adolescents: Scale development and educational correlates. Psychology in the Schools, 30(1), 79-90. https://doi.org/10.1002/1520-6807(199301)30:1<79::AID-PITS2310300113>3.0.CO;2-X

Hair, J. F., Jr., Black, W. C., Babin, B. J., \& Anderson, R. E. (2010). Multivariate data analysis: A global perspective. Upper Saddle, NJ: Pearson.

Heitzmann, C. A., \& Kaplan, R. M. (1988). Assessment of methods for measuring social support. Health Psychology, 7(1), 75-109. https://doi.org/10.1037/0278-6133.7.1.75

Hsieh, T.-L. (2016). Motivation categories in college students' learning engagement behaviors and outcomes in Taiwan: An application of cluster analysis. International Journal of Research Studies in Education, 5(4), 19-30. https://doi.org/10.5861/ijrse.2016.1222

Hu, L. T., \& Bentler, P. M. (1999). Cutoff criteria for fit indexes in covariance structure analysis: Conventional criteria versus new alternatives. Structural Equation Modeling: A Multidisciplinary Journal, 6(1), 1-55. https://doi.org/10.1080/10705519909540118

Hu, Y.-L., Ching, G. S., \& Chao, P.-C. (2012). Taiwan student engagement model: Conceptual framework and overview of psychometric properties. International Journal of Research Studies in Education, 1(1), 69-90. https://doi.org/10.5861/ijrse.2012.v1i1.19

Hu, Y.-L., Ching, G. S., \& Hung, C.-H. (2015). Comparison of concepts within the residential colleges in Taiwan. International Journal of Information and Education Technology, 5(12), 936-940. https://doi.org/10.7763/IJIET.2015.V5.641

Hu, Y.-L., Hung, C.-H., \& Ching, G. S. (2015). Student-faculty interaction: Mediating between student engagement factors and educational outcome gains. International Journal of Research Studies in Education, 4(1), 43-53. https://doi.org/10.5861/ijrse.2014.800

Hu, Y.-L., Hung, G.-C., Ching, G. S., \& Liao, C.-F. (2013). Reviving the concept of residential college in Taiwan: An introductory study. In International proceedings of economics development and research (Vol. 64, pp. 12-16). Singapore: IACSIT Press.

Jacobson, M. J., \& Wilensky, U. (2006). Complex systems in education: Scientific and educational importance and implications for the learning sciences. Journal of the Learning Sciences, 15(1), 11-34. https://doi.org/10.1207/s15327809jls1501_4 
Unmasking the role of teachers, peers, and administrators support towards the promotion of student engagement

Kaplan, B. H., Cassel, J. C., \& Gore, S. (1977). Social support and health. Medical Care, 15(5), 47-58. https://doi.org/10.1097/00005650-197705001-00006

Komarraju, M., Musulkin, S., \& Bhattacharya, G. (2010). Role of student-faculty interactions in developing college students' academic self-concept, motivation, and achievement. Journal of College Student Development, 51(3), 332-342. https://doi.org/10.1353/csd.0.0137

Kuh, G. D. (2001). The national survey of student engagement: Conceptual framework and overview of psychometric properties. Bloomington, IN: Indiana University Center for Postsecondary Research and Planning.

Kuh, G. D. (2009). The national survey of student engagement: Conceptual and empirical foundations. New Directions for Institutional Research, 2009(141), 5-20. https://doi.org/10.1002/ir.283

Kuh, G. D., Cruce, T. M., Shoup, R. S., Kinzie, J., \& Gonyea, R. M. (2008). Unmasking the effects of student engagement on first-year college grades and persistence. The Journal of Higher Education, 79(5), 540-563. https://doi.org/10.1080/00221546.2008.11772116

Kuh, G. D., \& Hu, S. (2001). The effects of student-faculty interaction In the 1990s. The Review of Higher Education, 24(3), 309-332. https://doi.org/10.1353/rhe.2001.0005

Lemanski, L., \& Van Deventer, M. M. (2019). A framework for the redesign principles that improved engagement in an online graduate class. In K. Walters \& P. Henry (Eds.), Fostering multiple levels of engagement in higher education environments (pp. 49-75). Hershey, PA: IGI Global. https://doi.org/10.4018/978-1-5225-7470-5.ch003

Määttä, K., \& Uusiautti, S. (2012). How to enhance the smoothness of university students' study paths? International Journal of Research Studies in Education, 1(1), 47-60. https://doi.org/10.5861/ijrse.2012.v1i1.16

Mackinnon, D. P., \& Dwyer, J. H. (1993). Estimating mediated effects in prevention studies. Evaluation Review, 17(2), 144-158. https://doi.org/10.1177/0193841X9301700202

MacKinnon, D. P., Lockwood, C. M., Hoffman, J. M., West, S. G., \& Sheets, V. (2002). Comparison of methods to test mediation and other intervening variable effects. Psychological Methods, 7, 83-104. https://doi.org/10.1037/1082-989X.7.1.83

Malecki, C. K., \& Demaray, M. K. (2006). Social support as a buffer in the relationship between socioeconomic status and academic performance. School Psychology Quarterly, 21(4), 375-395. https://doi.org/10.1037/h0084129

Malecki, C. K., \& Demary, M. K. (2002). Measuring perceived social support: Development of the child and adolescent social support scale. Psychology in the Schools, 39(1), 1-18. https://doi.org/10.1002/pits.10004

Pearson, J. E. (1986). The definition and measurement of social support. Journal of Counselling and Development, 64(6), 390-395. https://doi.org/10.1002/j.1556-6676.1986.tb01144.x

Perrenet, J. C., Bouhuijs, P. A. J., \& Smits, J. G. M. M. (2000). The suitability of problem-based learning for engineering education: Theory and practice. Teaching in Higher Education, 5(3), 345-358. https://doi.org/10.1080/713699144

Sarason, I. G., Sarason, B. R., Shearin, E. N., \& Pierce, G. R. (1987). A brief measure of social support: Practical and theoretical implications. Journal of Social and Personal Relationships, 4(4), 497-510. https://doi.org/10.1177/0265407587044007

Sax, L. J. (2004). Citizenship development and the American college student. New Directions for Institutional Research, 2004(122), 65-80. https://doi.org/10.1002/ir.110

Shrout, P. E., \& Bolger, N. (2002). Mediation in experimental and nonexperimental studies: New procedures and recommendations. Psychological Methods, 7(4), 422-445. https://doi.org/10.1037/1082-989X.7.4.422

Shumaker, S. A., \& Brownell, A. (1984). Toward a theory of social support: Closing conceptual gaps. Journal of Social Issues, 40(4), 11-36. https://doi.org/10.1111/j.1540-4560.1984.tb01105.x

Sobel, M. E. (1982). Asymptotic confidence intervals for indirect effects in structural equation models. Sociological Methodology, 13, 290-312. https://doi.org/10.2307/270723

Tucker, L. R., \& Lewis, C. (1973). A reliability coefficient for maximum likelihood factor analysis. Psychometrika, 38(1), 1-10. https://doi.org/10.1007/BF02291170

Turner, R. J. (1981). Social support as a contingency in psychological well-being. Journal of Health and Social Behavior, 22(4), 357-367. https://doi.org/10.2307/2136677

Wilcox, P., Winn, S., \& Fyvie-Gauld, M. (2005). It was nothing to do with the university, it was just the people: The role of social support in the first-year experience of higher education. Studies in Higher Education, 30(6), 707-722. https://doi.org/10.1080/03075070500340036

Zimet, G. D., Dahlem, N. W., Zimet, S. G., \& Farley, G. K. (1988). The multidimensional scale of perceived social support. Journal of Personality Assessment, 52(1), 30-41. 
Hu, Y.-L., \& Ching, G. S.

https://doi.org/10.1207/s15327752jpa5201_2

Zimet, G. D., Powell, S. S., Farley, G. K., Werkman, S., \& Berkoff, K. A. (1990). Psychometric characteristics of the multidimensional scale of perceived social support. Journal of Personality Assessment, 55(3-4), 610-617. https://doi.org/10.1080/00223891.1990.9674095 